\title{
Depth habitat of the planktonic foraminifera Neogloboquadrina pachyderma in the northern high latitudes explained by sea-ice and chlorophyll concentrations
}

\author{
Mattia Greco $^{1}$, Lukas Jonkers ${ }^{1}$, Kerstin Kretschmer ${ }^{1}$, Jelle Bijma ${ }^{2}$, and Michal Kucera ${ }^{1}$ \\ ${ }^{1}$ MARUM - Center for Marine Environmental Sciences, Leobener Str. 8, 28359, Bremen, Germany \\ ${ }^{2}$ Section Marine Biogeosciences, Alfred Wegener Institute Helmholtz Centre for Polar and Marine Research, \\ Bremerhaven, Germany
}

Correspondence: Mattia Greco (mgreco@marum.de)

Received: 4 March 2019 - Discussion started: 7 March 2019

Revised: 18 June 2019 - Accepted: 10 July 2019 - Published: 12 September 2019

\begin{abstract}
Neogloboquadrina pachyderma is the dominant planktonic foraminifera species in the polar regions. In the northern high-latitude ocean, it makes up more than $90 \%$ of the total assemblages, making it the dominant pelagic calcifier and carrier of paleoceanographic proxies. To assess the reaction of this species to a future shaped by climate change and to be able to interpret the paleoecological signal contained in its shells, its depth habitat must be known. Previous work showed that $N$. pachyderma in the northern polar regions has a highly variable depth habitat, ranging from the surface mixed layer to several hundreds of metres below the surface, and the origin of this variability remained unclear. In order to investigate the factors controlling the depth habitat of $N$. pachyderma, we compiled new and existing population density profiles from 104 stratified plankton tow hauls collected in the Arctic and the North Atlantic oceans during 14 oceanographic expeditions. For each vertical profile, the depth habitat (DH) was calculated as the abundanceweighted mean depth of occurrence. We then tested to what degree environmental factors (mixed-layer depth, sea surface temperature, sea surface salinity, chlorophyll $a$ concentration, and sea ice concentration) and ecological factors (synchronized reproduction and daily vertical migration) can predict the observed DH variability and compared the observed DH behaviour with simulations by a numerical model predicting planktonic foraminifera distribution. Our data show that the DH of N. pachyderma varies between 25 and $280 \mathrm{~m}$ (average $\sim 100 \mathrm{~m}$ ). In contrast with the model simulations, which indicate that DH is associated with the depth of chlorophyll maximum, our analysis indicates that the presence of
\end{abstract}

sea ice together with the concentration of chlorophyll $a$ at the surface have the strongest influence on the vertical habitat of this species. N. pachyderma occurs deeper when sea ice and chlorophyll concentrations are low, suggesting a timetransgressive response to the evolution of (near) surface conditions during the annual cycle. Since only surface parameters appear to affect the vertical habitat of $N$. pachyderma, light or light-dependant processes might influence the ecology of this species. Our results can be used to improve predictions of the response of the species to climate change and thus to refine paleoclimatic reconstructions.

\section{Introduction}

Neogoboquadrina pachyderma is the most abundant planktonic foraminifera in the Arctic Ocean and its marginal seas, where it also dominates the pelagic calcite production (Schiebel et al., 2017; Volkmann, 2000). When the organism dies, its calcite shells sink to the seafloor and when preserved in the sediments, it serves as a source of information on the physical state of the ocean in the past (Eynaud, 2011; Kucera, 2007). To understand the origin of the paleoceanographic proxy signal and to predict the production of the species under varying physical conditions, including projected future change scenarios, it is important to constrain the factors that determine its vertical habitat. Previous work has shown that the seasonality of $N$. pachyderma production follows the timing of food availability, which is tightly linked with temper- 
ature (Jonkers and Kucera, 2015; Tolderlund and Bé, 1971). On the other hand, the vertical habitat of the species is variable and appears hard to predict (Xiao et al., 2014).

Previous studies proposed different abiotic factors as drivers of $N$. pachyderma vertical distribution including temperature (Carstens et al., 1997; Carstens and Wefer, 1992; Ding et al., 2014), density stratification (Simstich et al., 2003), and the depth of the subsurface chlorophyll maximum indicating food availability (Kohfeld and Fairbanks, 1996; Pados and Spielhagen, 2014; Volkmann, 2000). Next to environmental factors, the behaviour of the species itself, such as its ontogenetic vertical migration (Bijma et al., 1990; Erez, 1991) and day-night migration (Field, 2004), or morphologically hidden cryptic diversity (Weiner et al., 2012), could also influence the vertical habitat observed in a single profile. However, the Arctic and the North Atlantic are inhabited by a single $N$. pachyderma genotype (Type I) (Darling et al., 2007), indicating that the variable depth habitat of the species cannot be attributed to cryptic diversity. On the other hand, analysis of the size distribution of $N$. pachyderma shells in the Arctic by Volkmann (2000) suggested a synchronized reproduction around the full moon, with sexually mature individuals descending towards a deeper habitat to release gametes. Similarly, diel vertical migration (DVM) is known to confound observations of vertical distribution patterns of Arctic plankton (Berge et al., 2009). Although the only study on DVM in polar waters on $N$. pachyderma showed no evidence of this phenomenon (Manno and Pavlov, 2014), it was based on observations during the midnight sun with relatively weak changes in light intensity, and the existence of DVM in $N$. pachyderma during other times of the year cannot be firmly ruled out. Therefore, the influence of the two ecological patterns on the depth habitat of $N$. pachyderma has to be considered in the analysis of our compilation of vertical profiles.

The lack of consensus on potential drivers of habitat variability in N. pachyderma calls for a systematic approach synthesizing new and existing observations into the same conceptual framework. In addition, there is now an opportunity to compare observations with predictions of a numerical model in the same framework. This opportunity arises from the recently extended model PLAFOM2.0, which can predict the seasonal and vertical habitat of Neogloboquadrina pachyderma (Kretschmer et al., 2018). This model is driven by temperature, food concentration, and light availability (which matters only for species with symbionts). The species-specific food concentrations are simulated by the Community Earth System Model, version 1.2.2 (CESM1.2; Hurrell et al., 2013) at every time step and are subsequently used by PLAFOM2.0 to calculate the monthly carbon concentration of $N$. pachyderma and four other species of planktonic foraminifera.

Here, we assembled existing vertical population density profiles of this species from the Arctic and North Atlantic, combined these with new observations from the Baffin Bay, and associated the observations with oceanographic data. Based an analysis of this dataset, we present a new concept that explains depth habitat variability in this important high-latitude marine calcifier. Next to three previously proposed environmental drivers of habitat variability (temperature, stratification, food availability), we also consider chlorophyll concentration at the surface as a measure of productivity, as well as salinity and sea-ice concentration. These parameters were included in order to test (i) the possibility that the foraminifera are attracted to food at the surface, (ii) the possibility of the foraminifera evading low-salinity surface layers, and (iii) the possibility that the foraminifera habitat responds to sea-ice-related variability in light, atmospheric exchange, and/or mixing.

\section{Material and methods}

Our analysis is based on a synthesis of existing and new vertical abundance profiles of $N$. pachyderma from the high northern latitudes. We exclude the Pacific Ocean because it is inhabited by a distinct genetic type of $N$. pachyderma with potentially different ecology (Darling et al., 2007). We compiled 97 population density profiles of N. pachyderma collected during 13 oceanographic expeditions between 1987 and 2011 (Fig. 1). We excluded one profile from Jensen (1998), station 37/6, where the abundance maximum occurred anomalously deep (below $500 \mathrm{~m}$ ) and which we thus suspect to reflect an error (i.e. due to sample mislabelling). We retained all other profiles, despite the differences in the sampling design (mesh size and vertical resolution of the sampled depth intervals) and in counted size fraction. The compilation is representative of the Eurasian Arctic Ocean and its marginal seas, as well as of the North Atlantic, but contains no data from the oceanographically distinct Baffin Bay. To fill this gap, we extended the compilation by generating new data from eight plankton tow profiles collected during the MSM09 cruise in 2008 (Fig. 1). At all stations sampling was carried out down to $300 \mathrm{~m}$ using a multiple closing plankton net (Hydro-Bios, Kiel) with a $50 \mathrm{~cm} \times 50 \mathrm{~cm}$ opening and a $100 \mu \mathrm{m}$ mesh (Kucera et al., 2014). The vertical distribution of planktonic foraminifera was resolved to nine levels by conducting two casts at each station (300-220, 220-180, 180-140, 140-100, 100-80, 80-60, 60-40, 40-20, $20-0 \mathrm{~m}$ ). After collection, net residues from each depth were concentrated on board, settled and decanted, filled up with $37 \%$ formaldehyde to a concentration of $4 \%$ and buffered to pH 8.5 using pure solid hexamethylenetetramine $\left(\mathrm{C}_{6} \mathrm{H}_{12} \mathrm{~N}_{4}\right)$ to prevent dissolution, and refrigerated. Specimens of planktonic foraminifera were picked from the wet samples under a binocular microscope and air-dried. All individuals in the fraction above $100 \mathrm{~mm}$ were counted and identified to species level following the classification of Hemleben et al. (1989) and Brummer and Kroon (1988). Full (cytoplasmbearing) tests were counted separately and considered living 


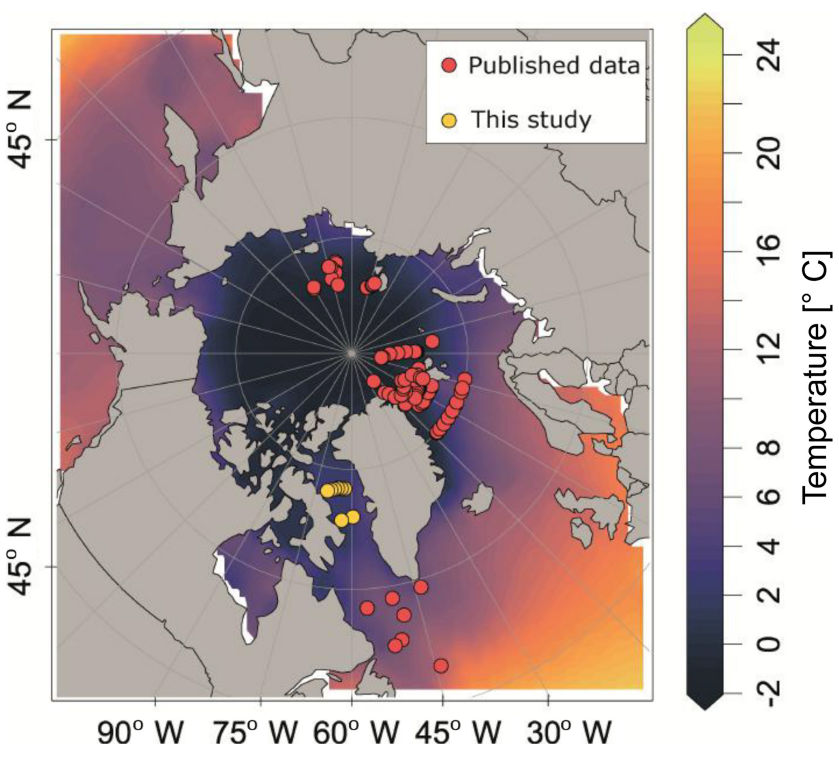

Figure 1. Plankton net stations with vertically resolved N. pachyderma counts that were used in this study. Background colour indicates the mean summer sea surface temperature (SST) (data from World Ocean Atlas 2013, Locarnini et al., 2013).

at the time of sampling. Counts were converted to concentration using the volume of filtered water determined from the product of towed interval height and the net opening $\left(0.25 \mathrm{~m}^{2}\right)$

For the new profiles from the Baffin Bay, water temperature and salinity were measured with a conductivitytemperature-depth (CTD) device deployed before each plankton tow. A submersible fluorospectrometer (bbe Moldaenke $\mathrm{GmbH}$ ) was used for the stations MSM09/457, MSM09/458, MSM09/460, and MSM09/462 to obtain vertical profiles of algae pigment concentrations from the surface to $300 \mathrm{~m}$ depth (Kucera et al., 2014). For the remaining profiles from the literature, physical oceanographic data and chlorophyll $a$ concentration profiles for each station were, if available, obtained from CTD profiles retrieved from the PANGAEA data repository using the R package "pangaear" (Simpson and Chamberlain, 2018; R Core Team, 2017). Sea surface parameters, sea surface temperature (SST), sea surface salinity (SSS), and surface chlorophyll concentration, were obtained from CTD profiles and Niskin bottles by averaging all the values from the first $5 \mathrm{~m}$. The depth of the chlorophyll maximum (DCM) was determined from vertical profiles of chlorophyll concentration obtained from either water column profiles or discrete measurements from Niskin bottles. The depth of the mixed layer (MLD), defined as the depth where in situ water density varied by more than $0.03 \mathrm{~kg} \mathrm{~m}^{-3}$ as in De Boyer Montegut et al. (2004), was calculated from the CTD profile of each station using a custom function in R. No vertically resolved profiles of environmental variables were available for plankton net hauls col-
Table 1. Results of the $t$ test performed on the samples collected in normal day-night conditions to assess the effects of DVM on DH.

\begin{tabular}{lrrrrr}
\hline Time of the day & $n$ & Mean DH $(\mathrm{m})$ & $\mathrm{SD}$ & $t$ value & $p$ value \\
\hline Night & 19 & 99.069 & 46.762 & -1.82 & 0.08 \\
Day & 9 & 66.949 & 35.401 & & \\
\hline
\end{tabular}

lected during the expeditions NEWP93, ARK-IV/3, ARK$\mathrm{X} / 1, \mathrm{ARK}-\mathrm{X} / 2, \mathrm{M} 36 / 3$, and M39/4. These profiles could thus only be used for the analysis of ontogenetic and diel vertical migration. In addition to the in situ data, daily sea ice concentrations for the location of all 104 sites included were extracted from $25 \mathrm{~km} \times 25 \mathrm{~km}$ resolution passive microwave satellite raster imagery obtained from the National Snow and Ice Data Centre (Boulder, Colorado, USA, Cavalieri et al., 1996) for 1979-2011 using a custom function in $R$. We used the data to determine sea-ice concentration at the time of collection and also to retrieve the time after sea-ice break for all stations that were sea-ice free at the moment of sampling. The date of the most recent sea-ice concentration maximum was used to retrieve the time by subtracting the days until the time of collection. Finally, the time of the collection was compared to the time of sunrise and sunset for each station determined using the R package "SunCalc" (Agafonkin and Thieurmel, 2018) to distinguish daytime and night-time collections. The sampling date was used to determine the lunar day using the R package "lunar" (Lazaridis, 2015).

The cross plots in Fig. 2 show how the final compilation of 104 profiles covers the environmental space and how the observations are spread across the seasons and the lunar cycle. The sampling is strongly biased towards the summer but the lunar cycle is completely covered. Most of the profiles were collected under midnight sun conditions, leaving only 28 profiles that could be used to test the diel vertical migration (Table 1). The profiles cover SST conditions between -2 and $7{ }^{\circ} \mathrm{C}$ and contain profiles taken across the entire range of sea-ice concentrations. Since sea-ice concentration at the studied profiles was not linearly related to SST, the compilation should allow us to assess the effect of the two variables independently (Fig. 2c). Productivity, expressed as surface chlorophyll $a$ concentration, is not correlated with temperature. The most productive stations were located in the Baffin Bay and in the Fram Strait with surface chlorophyll concentrations ranging between 2 and $4 \mathrm{mg} \mathrm{m}^{-3}$ (Fig. 2d). Surface salinity was mostly around $33 \mathrm{PSU}$; only in the Laptev Sea did values drop below 30 PSU.

To facilitate the analysis of depth habitat across density profiles with observations at different depth intervals, the density profiles were summarized into a single parameter, DH (depth habitat), which is the abundance-weighted mean depth calculated using the midpoints of the collection intervals (Fig. 3), as in Rebotim et al. (2017). The precision with which the $\mathrm{DH}$ can be determined is linked to the vertical res- 
(a)

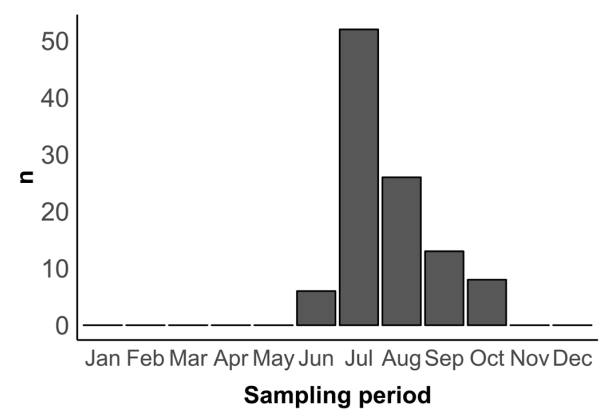

(c)

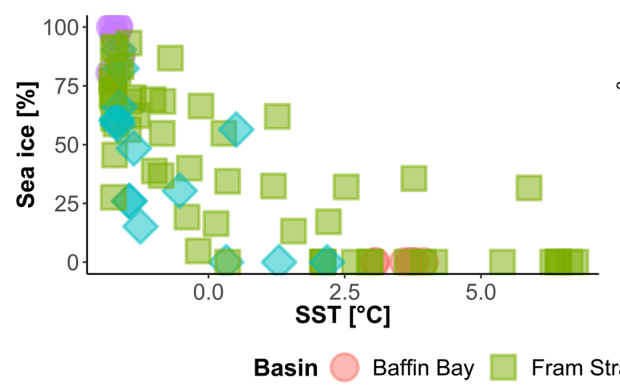

(b)

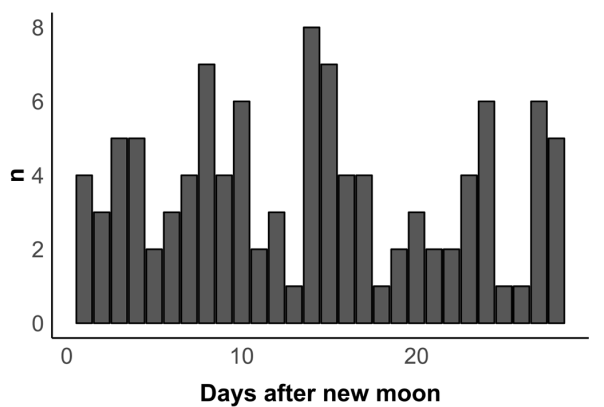

(d)

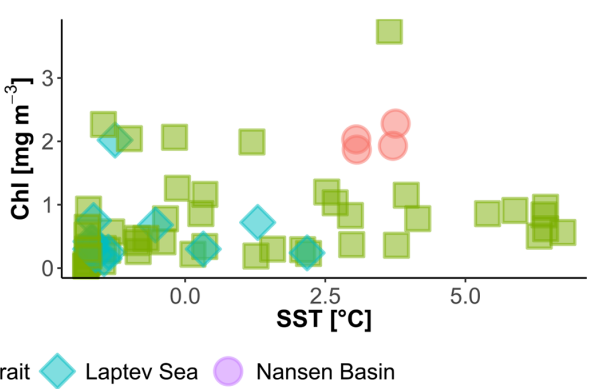

Figure 2. Temporal and environmental coverage of the vertical profiles of $N$. pachyderma concentration included in the study. The distribution of (a) the months and (b) days of the synodic lunar cycle of sample collection, showing a summer bias but even coverage of the lunar cycle. The relationship between the environmental conditions during sample collection (c-d) indicates the extent of the sampled environmental space.

olution of the profiles. The combined analysis of casts with different vertical resolution therefore unavoidably introduces some random noise in the DH estimates, but this does not compromise the first-order results of our study. Since counts of living and dead specimens were not available for all the stations, total counts were considered. However, where possible, we also derived the average living depth (ALD) to assess possible biases deriving from using total counts to constrain depth habitat. This comparison showed that ALD was highly correlated with DH and on average $11 \mathrm{~m}$ shallower than DH, which thus represents a slight systematic overestimation of the actual living depth of $N$. pachyderma (Fig. 4). Exceptions are stations MSM09/466, MSM55/84, and MSM36/069 where the observed ALD was deeper than DH due to the high number of dead specimens in the upper catch intervals. The appropriateness of a single parameter (DH) as an indicator of the distribution of $N$. pachyderma in the water column was further tested using a multivariate approach. We determined profile-standardized concentrations calculated for five depths $(0-50,50-100,100-200,200-300$, $300-500 \mathrm{~m}$ ) for all the stations and performed a principal component analysis (PCA) on the relative abundances in the sampling intervals using the R package "vegan" (Oksanen et al., 2018). The two first principal components explained $43 \%$ and $32 \%$ of the total variance in the relative abundance in the water column. The first axis exhibited negative loadings for the deeper intervals $(100-200,200-300,300$ $500 \mathrm{~m}$ ) and positive loadings for shallow intervals $0-50$ and $50-100 \mathrm{~m}$, indicating that it describes a depth-changing unimodal distribution (Fig. 4b). Mapped on the PC1 loadings, DH showed a significant correlation (Pearson $r=-0.88$, $p$ value $<0.01)$ indicating that all profiles had a single maximum and the depth distribution can be collapsed into a single variable (Fig. 4b).

We start our analysis by considering the potential effect of DVM and the possibility of synchronized vertical ontogenetic migration associated with the lunar cycle. Despite its potential importance (Rebotim et al., 2017), we cannot analyse seasonal variation in depth habitat because only a single season was sampled. The influence of DVM on DH was assessed by dividing samples in two groups based on whether they were collected during the day or during the night. The two groups were tested for homoscedasticity (homogeneity in variances) using an $F$ test, and then a $t$ test was performed to verify if there was a significant difference in the $\mathrm{DH}$ of day and night populations. To investigate the effects of the lunar cycle on the depth habitat of $N$. pachyderma, we used a periodic regression following the approach described in Jonkers and Kucera (2015). In the next step, we analysed the relationship between DH and sea surface temperature, sea surface salinity, mixed-layer depth, surface chlorophyll concentration, depth of chlorophyll maximum, and sea-ice concentra- 


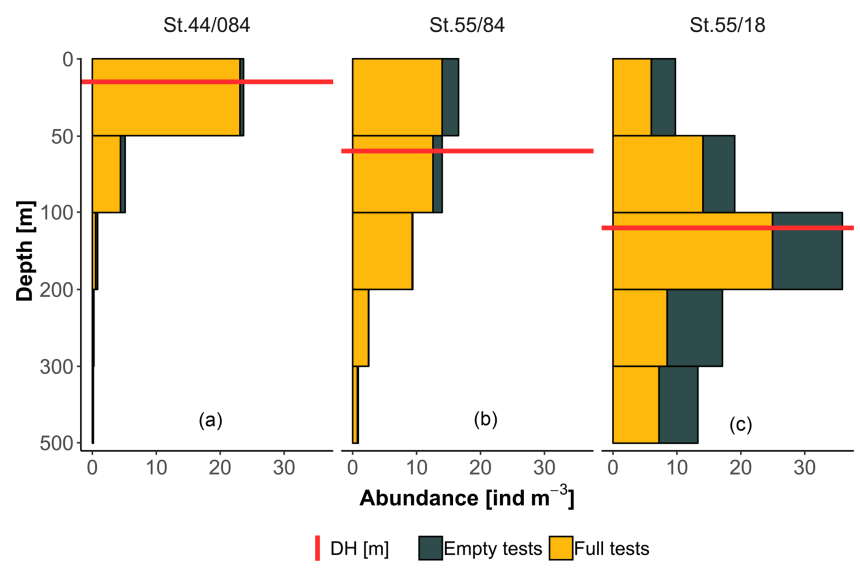

Figure 3. Example of vertical profiles from three stations included in the study displaying shallow (a), intermediate (b), and deep (c) depth habitat (DH).

tion. We use linear regression to assess if any of the variables individually predict a significant part of the DH variability, and the variables that showed significant correlation with $\mathrm{DH}$ were used to construct a multiple linear regression model allowing interactions. The use of linear regression assumes normality, which was tested, and linearity in the relationship, which is assumed, but prevents overfitting and therefore all estimates of goodness of fit in our models can be considered conservative.

\section{Results}

The DH values derived from the abundance profiles ranged from 26 to $283 \mathrm{~m}$ with an average of $100 \mathrm{~m}$ (IQR $=54.95$ ). The deepest observation comes from the Fram Strait, and the shallowest from the Baffin Bay.

An independent-sample $t$ test revealed no evidence for an effect of diel vertical migration on the observed N. pachyderma vertical distribution (Table 1). Similarly, the periodic regression showed no significant effect of lunar phase on DH ( $p=0.17$, adjusted $r^{2}=0.029$ ) (Table 2). In the subsequent analyses we could thus focus on abiotic factors in explaining vertical habitat variability in $N$. pachyderma. Bivariate linear regressions against DH carried out on a subset of 66 profiles for which all of the tested environmental parameters were available yielded a significant relationship only for chlorophyll concentration at the surface (Fig. 5a). However, we noticed that profiles from stations where sea ice was present appeared to show a relationship with sea-ice concentration and we thus carried out separate analyses for profiles with and without sea ice. We found no significant correlation between DH and the variables SST, SSS, MLD, and DCM in either the complete dataset or the subsets (Fig. 5a). Chlorophyll concentration at the surface appeared to be the only parameter showing significant negative correlation in both
Table 2. Results of the periodic regression performed to assess the influence of the lunar cycle on DH.

\begin{tabular}{lrr}
\hline & \multicolumn{2}{c}{ Depth habitat $(\mathrm{m})$} \\
\cline { 2 - 3 } Predictors & Estimates & $p$ \\
\hline sin $\left(\right.$ lunar day ${ }^{R}$ ) & -8.41 & 0.171 \\
$\cos ($ lunar day & $R$ \\
Observations & -10.39 & 0.071 \\
$R^{2}$ /adjusted $R^{2}$ & 104 & \\
\hline
\end{tabular}

the complete dataset $(r=-0.28, p<0.05)$ and the sea-icefree subset $(r=-0.60, p<0.01)$. A negative correlation between DH and sea-ice concentration was observed in the subset including ice-covered stations $(r=-0.38, p<0.05)$. Following the initial variable selection, where only profiles for which all variables were available were considered, we then extended the analyses to all profiles where sea-ice concentration and/or chlorophyll concentration at the surface were available. These analyses confirm the significance of the relationships (Fig. $5 \mathrm{~b}$ and c).

In the Arctic, the break-up of the sea ice is normally followed by a pulse of productivity (Leu et al., 2015), making the two tested variables potentially causally connected in a time-transgressive manner. To test for the presence of such a relationship, we tested the relationship between DH and the number of days since sea-ice break-up. To decrease the collinearity between sea ice and productivity, the analysis was restricted to 18 profiles from stations with chlorophyll concentrations $<0.5 \mathrm{mg} \mathrm{m}^{-3}$. This analysis shows that DH significantly increases with time after the sea-ice breakup $(r=0.65, p<0.01)$ (Fig. 6). In the final step, we combined the three variables that individually showed a significant effect on DH for at least one subset of the profiles and constructed a multiple regression model to predict the depth habitat of $N$. pachyderma based on sea-ice concentration and the interaction between chlorophyll concentration at surface and days after the sea-ice break. A linear formulation of the model is significant $(p<0.01)$ and the model explains $29 \%$ of the depth habitat variability in $N$. pachyderma (adjusted $r^{2}=0.29$ ). Next, we tested a non-linear relationship, considering the log-normal nature of the DH. This model leads to a marginal improvement (adjusted $r^{2}=0.34$ ) (Table 3).

Finally, we evaluate how PLAFOM2.0 (Kretschmer et al., 2018) captures the observed patterns in N. pachyderma depth habitat. To this end, we assess the relationship between modelled DH of $N$. pachyderma and modelled SST, SSS, MLD, DCM, and chlorophyll concentration for summer months in the geographic area covered by the compilation (Fig. 1). By comparing modelled with observed ecological patterns, rather than individual observations, we ensure a more meaningful evaluation of the model performance that does not rely on the simulation of individual profiles. Although PLAFOM2.0 simulations also indicate a domi- 
(a)

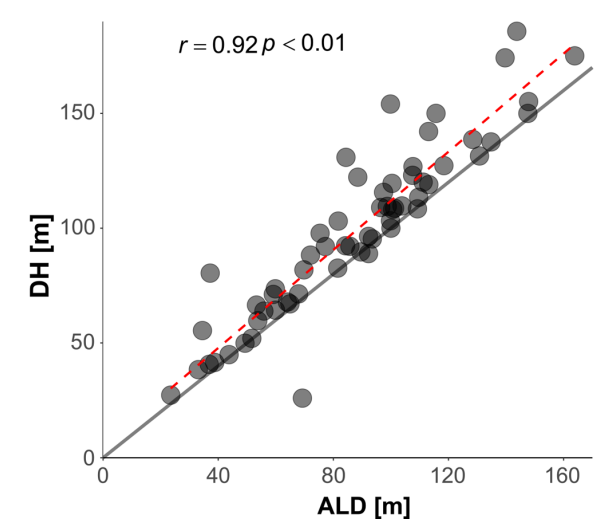

(b)

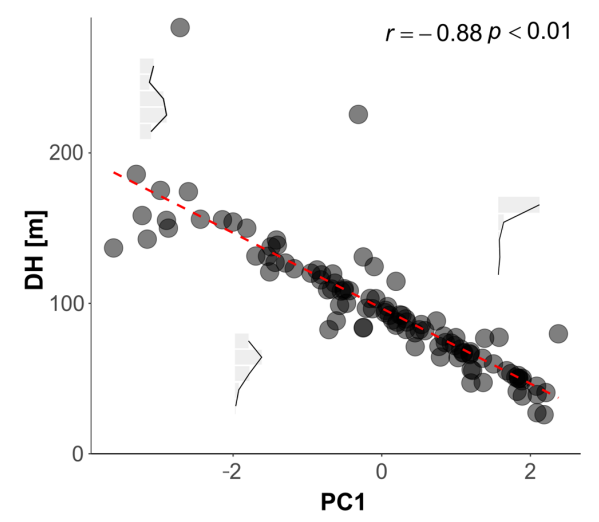

Figure 4. (a) Relationship between the depth habitat (DH) and the average living depth (ALD). The dashed red line shows the linear fit while the solid line represent the 1: 1 relationship between the two variables. (b) Relationship between the DH and the PC1 resulted from the PCA calculated on the normalized counts. The abundance profiles based on the standardized counts in the plot show examples of the shape of the vertical distribution of $N$. pachyderma for three values of PC1 loadings The dashed red line shows the linear fit.

\section{(a)}

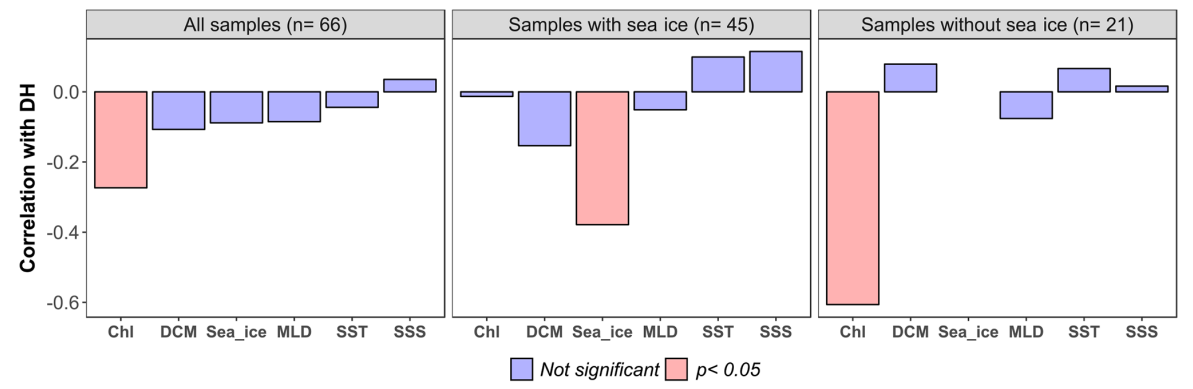

(b)

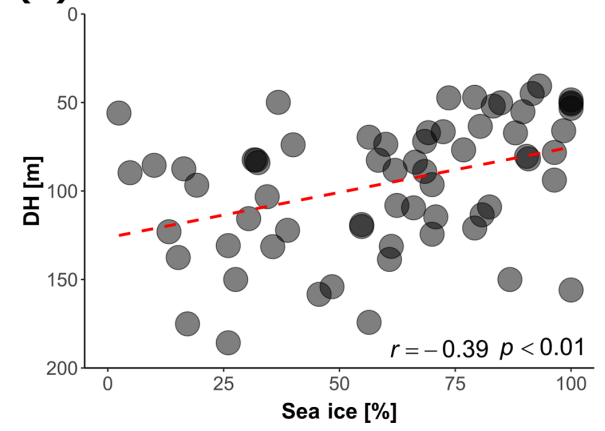

(c)

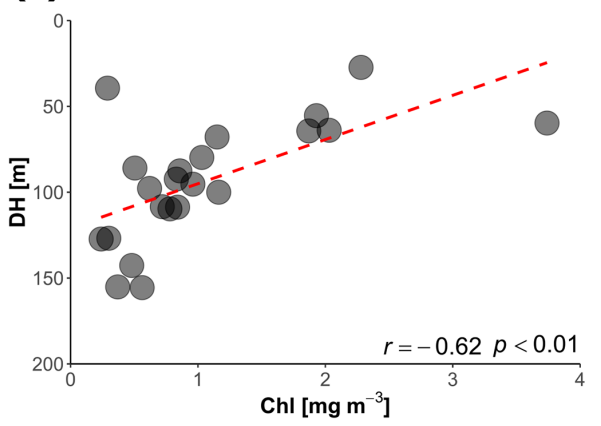

Figure 5. (a) Correlation between depth habitat (DH) and the environmental variables calculated at all the sites, in the subsets with sea ice and without sea ice (only sites where all the tested variables were available were considered). Chl: chlorophyll concentration at surface; Sea_ice: sea-ice coverage; DCM: depth of chlorophyll maximum; SST: sea surface temperature; MLD: depth of the mixed layer; SSS: sea surface salinity. (b) Relationship between DH and sea-ice concentration in the stations covered by sea ice (all the sites with available sea-ice data are shown, $n=65$ ). (c) Relationship between DH and chlorophyll concentration at the surface for the sea-ice-free stations (all the sites with available chlorophyll data are shown, $n=22$ ). The dashed red lines show the linear fit.

nantly subsurface summer depth habitat of $N$. pachyderma, the modelled DH is shallower than observed, with values ranging between 9 and $127 \mathrm{~m}$ (Fig. 7). Contrary to observations, the modelled $\mathrm{DH}$ shows the highest correlation with the depth of the mixed layer $(r=0.57, p<0.01)$. Moreover, the observed relationship between the modelled DH and the modelled sea-ice and chlorophyll concentrations is lower and of opposite sign to the observations (Fig. 8a-b). 
Table 3. Results of the multiple regression model including sea-ice concentration, chlorophyll concentration at surface, and time since sea-ice break-up as predictors.

\begin{tabular}{|c|c|c|c|c|c|c|}
\hline \multirow[b]{2}{*}{ Predictors } & \multicolumn{3}{|c|}{$\mathrm{DH}(\mathrm{m})$} & \multicolumn{3}{|c|}{$\log _{10}(\mathrm{DH})(\mathrm{m})$} \\
\hline & Estimates & CI & $p$ & Estimates & $\mathrm{CI}$ & $p$ \\
\hline (Intercept) & 110.76 & $80.37-141.15$ & $<0.001$ & 2.03 & $1.89-2.18$ & $<0.001$ \\
\hline Sea ice $(\%)$ & -0.04 & -0.08 to -0.00 & 0.033 & 0 & -0.00 to -0.00 & 0.021 \\
\hline $\begin{array}{l}\text { Chlorophyll at } \\
\text { surface }\left(\mathrm{mg} \mathrm{m}^{-3}\right)\end{array}$ & 10.94 & $-10.82-32.71$ & 0.329 & 0.06 & $-0.04-0.16$ & 0.263 \\
\hline $\begin{array}{l}\text { Days after sea ice } \\
\text { break-up }\end{array}$ & 0.71 & $0.22-1.20$ & 0.007 & 0 & $0.00-0.01$ & 0.005 \\
\hline $\begin{array}{l}\text { Interaction } \\
\text { (chlorophyll and sea-ice } \\
\text { break-up timing) }\end{array}$ & -0.81 & -1.25 to -0.37 & 0.001 & 0 & -0.01 to -0.00 & $<0.001$ \\
\hline Observations & & 52 & & & 52 & \\
\hline$R^{2} /$ adjusted $R^{2}$ & & $0.343 / 0.287$ & & & $0.388 / 0.336$ & \\
\hline
\end{tabular}

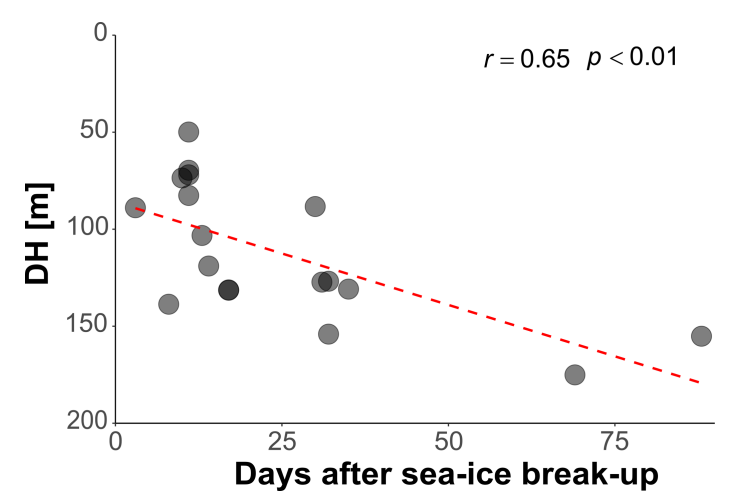

Figure 6. Relationship between depth habitat $(\mathrm{DH})$ and the time (days) after the sea-ice break-up. The dashed red line shows the linear fit.

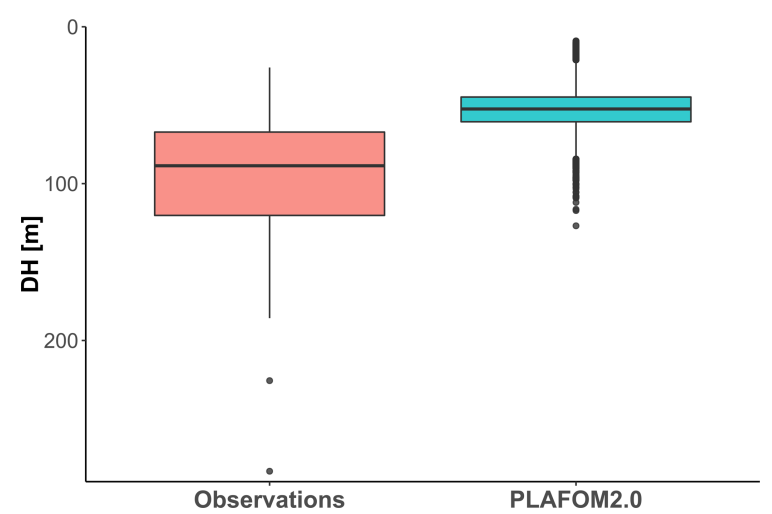

Figure 7. Comparison of observed DH and the PLAFOM2.0 predictions relative to the summer months in the same geographic area covered by our compilation.

\section{Discussion}

Previous research indicated the absence of DVM in N. pachyderma in the Fram Strait (Manno and Pavlov, 2014) but the fact that the sampling was carried out during the midnight sun led the authors to concede that the species could still engage in DVM in the presence of a diurnal light cycle. Indeed, studies on copepods in the Arctic showed that natural patchiness rather than DVM is responsible for shifts in vertical distribution in periods of midnight sun, while in late summerearly autumn, when changes in the diurnal light cycle are apparent, DVM can be observed (Blachowiak-Samolyk et al., 2006; Rabindranath et al., 2011). Our compilation allowed us to assess the behaviour of $N$. pachyderma under changing light conditions, but showed no evidence for DVM (Table 1). Similarly, a recent investigation on the presence of DVM in planktonic foraminifera from the tropical Atlantic found no evidence for this phenomenon in any of the analysed species (Meilland et al., 2019). Our observations thus add to the existing consensus that planktonic foraminifera are unlikely to participate in DVM. Although we cannot rule out DVM on a very small vertical or geographical scale, we conclude that the observed variability in habitat depth of $N$. pachyderma in our compilation is likely not biased by DVM, allowing us to investigate other potential drivers.

The reproduction of many species of planktonic foraminifera appears synchronized on a lunar or semilunar cycle (Bijma et al., 1990; Jonkers et al., 2015; Rebotim et al., 2017; Schiebel et al., 1997; Spindler et al., 1979), with sexually mature individuals descending towards a deeper habitat to release their gametes (Bijma et al., 1990; Erez, 1991). Volkmann (2000) analysed size distribution of $N$. pachyderma in the Arctic and found an indication for a synchronized descent of adult individuals below $60 \mathrm{~m}$ during the full moon. In our analysis of 104 density profiles, including those from Volkmann (2000), we found no evidence of a 
(a)

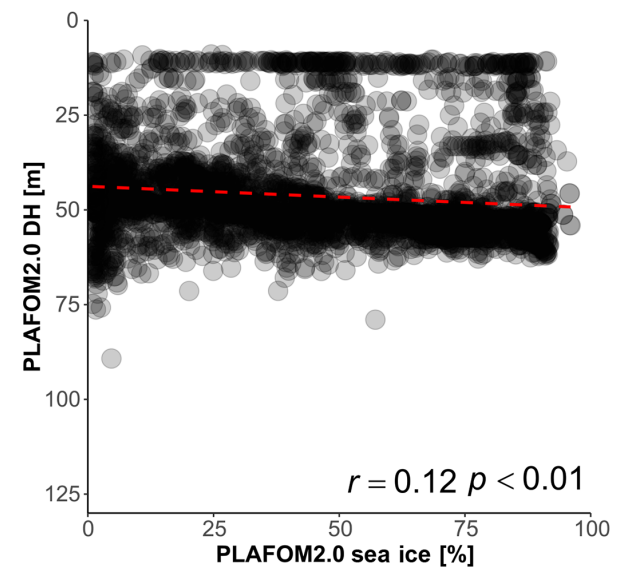

(b)

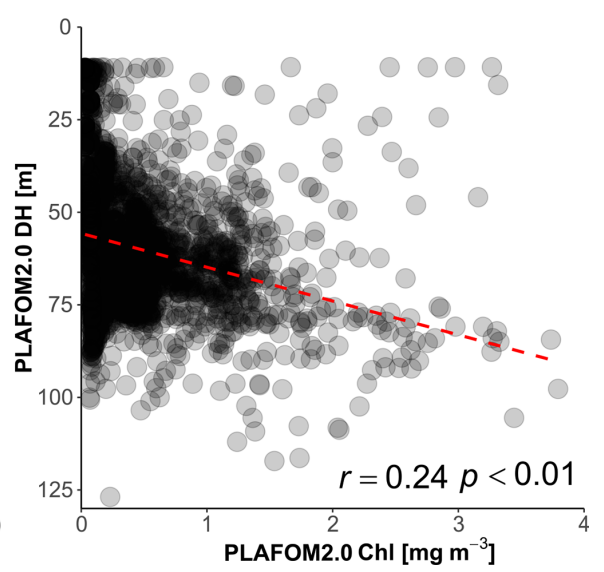

Figure 8. (a) Relationship between the DH predicted by PLAFOM2.0 and (a) sea-ice concentration in the stations covered by sea ice and (b) between DH predicted by PLAFOM2 and chlorophyll concentration at the surface for the sea-ice-free stations (values averaged for the months June, July, August, and September). The dashed red lines show the linear fit.

systematic shift towards deeper habitat associated with lunar periodicity (Table 2). Our analysis cannot resolve whether or not the reproduction in $N$. pachyderma is synchronized nor can we rule out an irregular ontogenetic vertical migration. However, the absence of a systematic relationship between DH and lunar cyclicity in our compilation indicates that a potential ontogenetic vertical migration would likely only contribute a noise component to the DH variability.

Considering all potential sources of noise, including the possibility of an irregular ontogenetic vertical migration, differences in the vertical resolution of the profiles and the counted size fractions, and the large geographical and temporal coverage of the data, it is remarkable that we observe a highly significant relationship between DH and three environmental parameters that collectively explain almost a third of the variance (Table 3). This indicates that the vertical habitat of N. pachyderma in the Arctic and North Atlantic changes systematically in response to sea-ice and chlorophyll concentrations at the surface. The absence of a systematic relationship with any other of the previously considered environmental drivers, like the position of the DCM or thickness of the mixed layer, is surprising. It implies that the ecophysiology of the species is not yet completely understood and this lack of understanding is also mirrored in the contrast between the environmental drivers inferred from observations and assumed in PLAFOM2.0 (Fig. 8).

There is general consensus that N. pachyderma grazes on phytoplankton and it would thus seem reasonable to assume that food availability primarily influences its vertical distribution (Bergami et al., 2009; Carstens et al., 1997; Kohfeld and Fairbanks, 1996; Pados and Spielhagen, 2014; Taylor et al., 2018; Volkmann, 2000). Surprisingly, our analysis yielded no significant correlation between the position of the subsurface chlorophyll maximum and DH. Instead, the
DH of the species is always located below DCM and thus most specimens of the population do not appear to be grazing at the DCM. This observation is also in contrast with the modelled relationship between DH and the environmental parameters. As also noted by Kretschmer et al. (2018), this is because the strong relationship between DH and MLD in the model reflects a strong link between MLD and the position of the subsurface chlorophyll maximum. This strong link likely results from a bias in the ocean component of the Community Earth System Model (CESM1.2) propagated in PLAFOM2.0. The CESM1.2 model is known to overestimate the mixed-layer depth in the Arctic by 20 to $40 \mathrm{~m}$ (Moore et al., 2013). In the model, this overestimation of the MLD affects ocean biogeochemistry and the light regime experienced by the phytoplankton. Specifically, a deeper mixed layer equates to a thicker layer of nutrient depletion, deepening the DCM. Consequently, the simulated depth of the chlorophyll maximum reaches 60 to $95 \mathrm{~m}$, whereas a recent survey of vertical chlorophyll profiles in the post-bloom period (May-September) in the Arctic indicated that subsurface chlorophyll maxima occur in the top $50 \mathrm{~m}$ (Ardyna et al., 2013), which is also in line with the range of DCM among the studied profiles (Fig. 9). Clearly, the observed preference of $N$. pachyderma for a habitat below the DCM (Fig. 9) indicates that the species may not primarily feed on fresh phytoplankton. The possibility of other species of Neogloboquadrina feeding on marine snow particles (hence below the DCM) has been recently suggested by Fehrenbacher et al. (2018), and a similar food source, related to degraded organic matter, is thus not unlikely for $N$. pachyderma.

Among the other previously considered abiotic drivers of depth habitat of $N$. pachyderma, our analysis provides no evidence for the effect of sea surface temperature, salinity, and stratification (Fig. 4). Surface water temperature is the main 


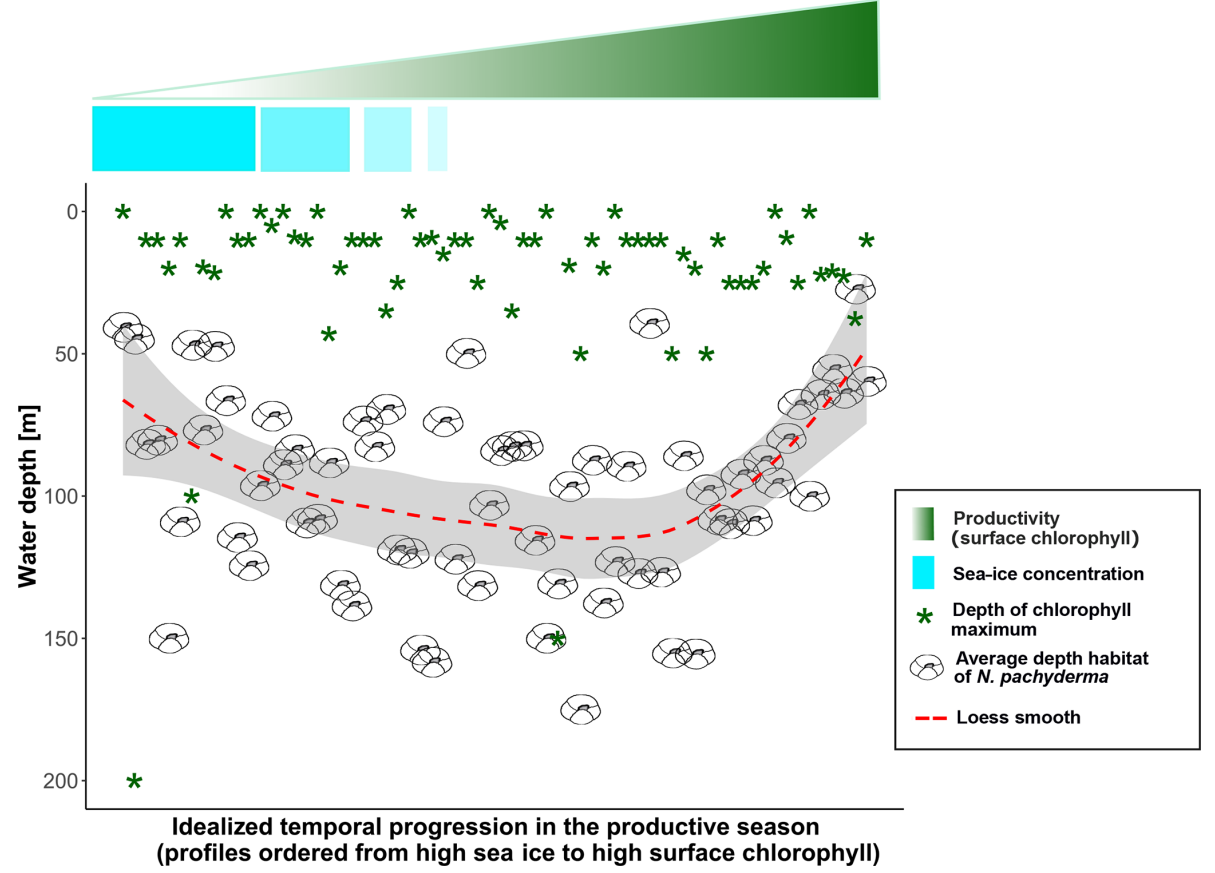

Figure 9. Data-based scheme of the final model: samples are displayed in descending order for sea-ice concentration (light-blue fading bar) and ascending chlorophyll concentration (green fading triangle) to simulate the time dimension. The green star symbols represent the depth of the chlorophyll maximum and the dashed red line shows the smooth fit of the data.

controller of N. pachyderma abundance and it defines its geographic range (Bé and Tolderlund, 1971; Duplessy et al., 1991). Temperature could therefore also be expected to influence the vertical habitat of the species. However, we found no link with surface temperature and $N$. pachyderma depth habitat. This is probably because the temperature range sampled by our compilation remains well within the tolerance limit of the species (Žarić et al., 2005). Thus, temperature does not represent a limiting factor for this species and does not affect its vertical distribution. Previous research has suggested that $N$. pachyderma may avoid low salinities and preferentially occur deeper in the water column when the surface is fresh (Volkmann, 2000; see also the discussion in Schiebel et al., 2017). Like Carstens and Wefer (1992), we did not find a significant correlation between surface salinity and DH indicating that the inferred response of $N$. pachyderma to surface layer freshening only applies to situations where the salinity reaches values below $30 \mathrm{PSU}$ (below the limit covered by the observations in our compilation). Finally, geochemical analyses of $N$. pachyderma specimens were interpreted as evidence for calcification depth of the species being controlled by the position of the pycnocline (Hillaire-Marcel, 2011; Hillaire-Marcel et al., 2004; Kozdon et al., 2009; Simstich et al., 2003; Xiao et al., 2014). In our data, we found DH always situated below the MLD, within the pycnocline. Thus, our observations confirm that a significant part of the calcification is likely to occur within the pycnocline, but the depth habitat of the species does not reflect the depth of the local pycnocline.

Our observations indicate that $N$. pachyderma resides closer to the surface when sea ice and/or surface chlorophyll concentrations are high. The DH also increases with time since sea-ice break-up. This suggests that the DH of $N$. pachyderma is controlled by multiple interacting variables, likely connected in the temporal dimension. The scheme in Fig. 9 summarizes our conceptual model: when either sea-ice cover or surface chlorophyll concentrations reach high values, $N$. pachyderma prefers shallower depths, while in open waters with low productivity levels, it lives deeper. While the relationship with sea ice has been observed repeatedly (Carstens et al., 1997; Pados and Spielhagen, 2014), the relationship with surface chlorophyll at the surface is unexpected. Intuitively, rather than sea ice and chlorophyll at the surface, the DH should reflect ambient conditions at depth. The DH does not appear to reflect the DCM (Fig. 9), but it could be that the species vertical abundance reflects the local depth at which a specific temperature or salinity optimum occurs or where a given density is realized. We have thus extracted data on temperature, salinity, and density at the level of DH in all profiles where CTD data were available. The analysis reveals a large variability in all parameters, indicating that the DH is not tracking specific temperature, salinity, or density (Fig. 10). The observation that the subsurface depth habitat of $N$. pachyderma appears to be best predicted 
(a)

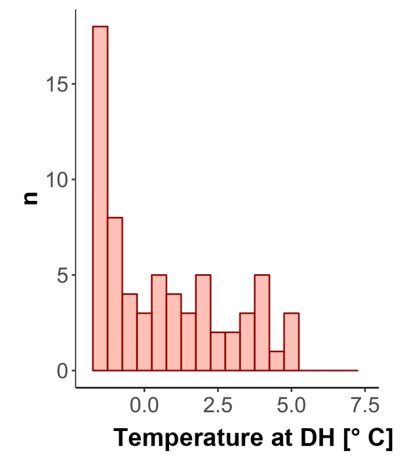

(d)

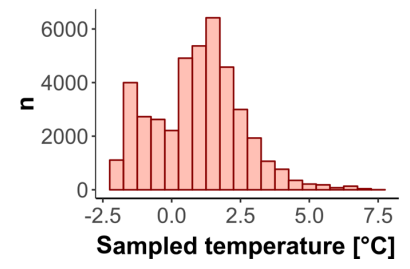

(b)

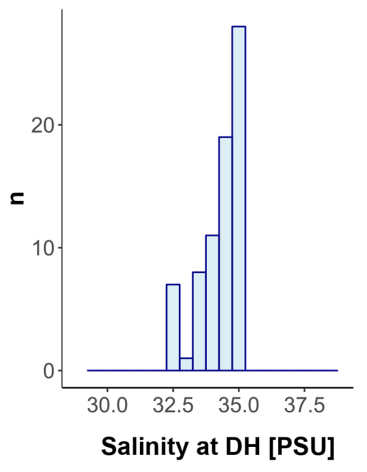

(e)

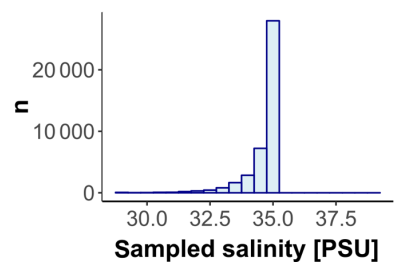

(c)

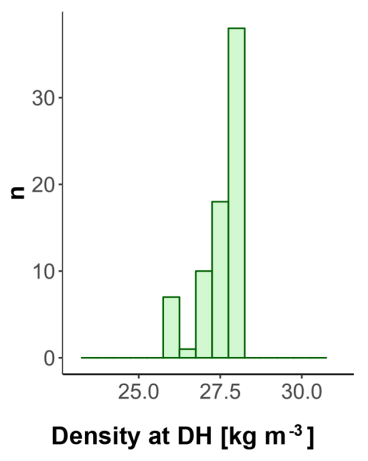

(f)

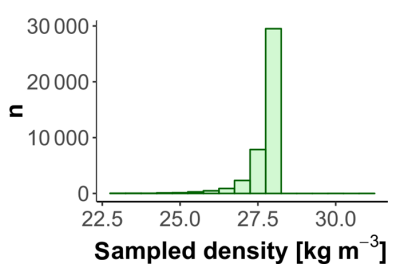

Figure 10. Conditions of $(\mathbf{a}, \mathbf{d})$ temperature, $(\mathbf{b}, \mathbf{e})$ salinity, and $(\mathbf{c}, \mathbf{f})$ density at the DH $(\mathbf{a}, \mathbf{b}, \mathbf{c})$ and in the first $600 \mathrm{~m}$ of the water column $(\mathbf{d}, \mathbf{e}, \mathbf{f})$ for all the sites with available CTD data.

by surface parameters is counter-intuitive and points to an indirect relationship to the inferred surface drivers.

A possible link between surface properties and conditions at the DH could be light (or light-related) processes. Increasing sea-ice cover and higher chlorophyll at the surface both act to reduce light penetration, potentially explaining why $N$. pachyderma habitat is shallow when either sea ice or surface chlorophyll is high (Fig. 9). The exact mechanism by which the species would respond to light intensity is not clear. So far, there is no evidence that the species would possess photosynthetically active symbionts. On the other hand, a recent molecular study indicated the presence of symbionts in a closely related species Neogloboquadrina incompta (Bird et al., 2018), and evidence for potential symbiosis with cyanobacteria in Globigerina bulloides (Bird et al., 2017) indicates that the range of symbioses in planktonic foraminifera may be more diverse than previously thought. However, half the observed DH values are below $100 \mathrm{~m}$, indicating that a substantial part of the population of the species inhabits a depth where in the Arctic light for photosynthesis is not available (Ardyna et al., 2013). Alternatively, it could be that the vertical habitat of $N$. pachyderma reflects a compromise between living close to the DCM (finding food) and remaining in darkness (protected from predation). In many places of the ocean, heterotrophic protists are known to be metabolically more active at night (Hu et al., 2018), and predator evasion by remaining in darkness is the leading hypothesis explaining DVM in marine zooplankton (Hays, 2003). These hypotheses are at present speculative and more investigations on the diet of $N$. pachyderma are needed for a better understanding of the process regulating its vertical distribution.

\section{Conclusions}

We compiled a dataset of 104 vertically resolved profiles of $N$. pachyderma concentration in the Arctic and North Atlantic and analysed the relationship of the observed depth habitat to a range of potential biotic and abiotic drivers. The analysis confirms that $N$. pachyderma inhabits a wide portion of the water column, but its maximum concentration is typically found in the subsurface. The depth habitat is variable but most of the population is consistently found below the subsurface chlorophyll maximum. This indicates that the species is likely not grazing on fresh phytoplankton. The depth habitat of $N$. pachyderma as recorded by the vertically resolved plankton tow profiles shows no evidence for diel vertical migration or a synchronized change in depth habitat with lunar cycle. Temperature, salinity, and density alone (at the surface or at depth) do not show a significant relationship with the depth habitat. Instead, sea-ice and chlorophyll concentrations at the surface, in combination with the time since sea-ice break-up, explain almost a third of the variance in the depth habitat data. Most of the population of N. pachyderma resides between 50 and $100 \mathrm{~m}$ under dense sea-ice coverage and/or high surface chlorophyll concentration. When sea-ice cover is reduced and/or when chlorophyll at the surface is low, the habitat deepens to $75-150 \mathrm{~m}$. This pattern reflects a response to an unknown primary driver acting below the DCM and likely reflecting trophic behaviour of the species, 
which is still poorly constrained. The knowledge gap on the ecological preferences of $N$. pachyderma is reflected in the mismatch in the behaviour of $N$. pachyderma between observations and predictions by the PLAFOM2.0 model. Our findings can serve as a basis to calibrate new ecosystem models and refine paleoclimatic reconstructions based on N. pachyderma in the Arctic and its adjacent seas. Our analysis rejects the hypothesis that the vertical habitat of the species is tied to the DCM, and the existence of a significant relationship with sea ice and surface chlorophyll allows us to derive a model that can predict the depth habitat of the species across the Arctic realm.

Data availability. PANGAEA reference for $N$. pachyderma counts from the stations sampled during the ARK-XI/1 expedition (Volkman and Stein, 2003), the ARK-XIII/2 expedition (Volkman and Stein, 2004), and during the cruises ARK XV/1, ARKXV/2, and M39/4 (Stangeew, 2001). The table complete with data sources and derived environmental data of the stations included in the study is available on Zenodo (https://doi.org/10.5281/zenodo.3375449, Greco, 2019). The table with $N$. pachyderma concentrations from stratified plankton tow hauls collected during the cruises NEWP-92, NEWP-93, ARK-IV/3, ARK-X/1, ARK-X/2, ARK$\mathrm{XI} / 2, \mathrm{M} 36 / 3$, MSM09/2, and ARKXXVI/1 is available on PANGAEA (https://doi.org/10.1594/PANGAEA.905270, Greco, 2019).

Author contributions. MK, LJ, and MG designed the study. KK provided the PLAFOM2.0 data. MG generated the data and carried out the analyses. All authors contributed to writing the paper.

Competing interests. The authors declare that they have no conflict of interest.

Acknowledgements. The master and crew of the F.S. Maria S. Merian are gratefully acknowledged for support of the work during the MSM09/2 cruise.

Financial support. This research has been supported by the Deutsche Forschungsgemeinschaft (DFG) through the International Research Training Group "Processes and impacts of climate change in the North Atlantic Ocean and the Canadian Arctic" (IRTG 1904 ArcTrain).

Review statement. This paper was edited by Lennart de Nooijer and reviewed by Robert F. Spielhagen, Antje Voelker, Katrine Husum, Caterina Bergami, and one anonymous referee.

\section{References}

Agafonkin, V. and Thieurmel, B.: Package "suncalc", version 0.5.0, available at: https://github.com/datastorm-open/suncalc (last access: 2 September 2019), 2018.

Ardyna, M., Babin, M., Gosselin, M., Devred, E., Bélanger, S., Matsuoka, A., and Tremblay, J.-É.: Parameterization of vertical chlorophyll $a$ in the Arctic Ocean: impact of the subsurface chlorophyll maximum on regional, seasonal, and annual primary production estimates, Biogeosciences, 10, 4383-4404, https://doi.org/10.5194/bg-10-4383-2013, 2013.

Bé, A. and Tolderlund, D. S.: Distribution and ecology of living planktonic foraminifera in surface waters of the Atlantic and Indian Oceans, in The Micropaleontology of Oceans, Cambridge University Press, Cambridge, 105-149, 1971.

Bergami, C., Capotondi, L., Langone, L., Giglio, F., and Ravaioli, M.: Distribution of living planktonic foraminifera in the Ross Sea and the Pacific sector of the Southern Ocean (Antarctica), Mar. Micropaleontol., 73, 37-48, https://doi.org/10.1016/j.marmicro.2009.06.007, 2009.

Berge, J., Cottier, F., Last, K. S., Varpe, Ø., Leu, E., Søreide, J., Eiane, K., Falk-Petersen, S., Willis, K., Nygård, H., Vogedes, D., Griffiths, C., Johnsen, G., Lorentzen, D., and Brierley, A. S.: Diel vertical migration of Arctic zooplankton during the polar night, Biol. Lett., 5, 69-72, https://doi.org/10.1098/rsbl.2008.0484, 2009.

Bijma, J., Erez, J., and Hemleben, C.: Lunar and semi-lunar reproductive cycles in some spinose Planktonic Foraminifers, J. Foramin. Res., 20, 117-127, 1990.

Bird, C., Darling, K. F., Russell, A. D., Davis, C. V., Fehrenbacher, J., Free, A., Wyman, M., and Ngwenya, B. T.: Cyanobacterial endobionts within a major marine planktonic calcifier (Globigerina bulloides, Foraminifera) revealed by $16 \mathrm{~S}$ rRNA metabarcoding, Biogeosciences, 14, 901-920, https://doi.org/10.5194/bg14-901-2017, 2017.

Bird, C., Darling, K. F., Russell, A. D., Fehrenbacher, J. S., Davis, V., Free, A., and Ngwenya, B. T.: 16S rRNA gene metabarcoding and TEM reveals different ecological strategies within the genus Neogloboquadrina (planktonic foraminifer) 13, 83-95, 2018.

Blachowiak-Samolyk, K., Kwasniewski, S., Richardson, K., Dmoch, K., Hansen, E., Hop, H., Falk-Petersen, S., and Mouritsen, L. T.: Arctic zooplankton do not perform diel vertical migration (DVM) during periods of midnight sun, Mar. Ecol. Prog. Ser., 308, 101-116, https://doi.org/10.3354/meps308101, 2006.

Brummer, G. J. and Kroon, D.: Planktonic foraminifers as tracers of cean-climate history, VU Uitgeverij, Amsterdam, 1988.

Carstens, J. and Wefer, G.: Recent distribution of planktonic foraminifera in the Nansen Basin, Arctic Ocean, DeepSea Res. Pt. A, 39, 507-524, https://doi.org/10.1016/S01980149(06)80018-X, 1992.

Carstens, J., Hebbeln, D., and Wefer, G.: Distribution of planktic foraminifera at the ice margin in the Arctic (Fram Strait), Mar. Micropaleontol., 29, 257-269, https://doi.org/10.1016/S03778398(96)00014-X, 1997.

Cavalieri, D. J., Parkinson, C. L., Gloersen, P., and Zwally, H. J.: updated yearly, Sea Ice Concentrations from Nimbus-7 SMMR and DMSP SSM/I-SSMIS Passive Microwave Data, Version 1. (1987-2011), Boulder, Colorado USA, NASA National Snow and Ice Data Center Distributed Active Archive Center, 
https://doi.org/10.5067/8GQ8LZQVL0VL (last access: 12 December 2017), 1996.

De Boyer Montegut, C., Madec, G., Fischer, A. S., Lazar, A., and Iudicone, D.: Mixed layer depth over the global ocean?: An examination of profile data and a profile-based climatology, J. Geophys. Res., 109, 1-20, https://doi.org/10.1029/2004JC002378, 2004.

Darling, K. F., Kucera, M., and Wade, C. M.: Global molecular phylogeography reveals persistent Arctic circumpolar isolation in a marine planktonic protist, P. Natl. Acad. Sci. USA, 104, 50025007, https://doi.org/10.1073/pnas.0700520104, 2007.

Duplessy, J.-C., Labeyrie, L., Juillet-Leclerc, A., Maitre, F., Duprat, J., and Sarntheinc, M.: Surface salinity reconstruction of the North Atlantic Ocean during the last glacial maximum, Oceanol. Ac., 14, 311-324, https://doi.org/10.1210/en.2002221113, 1991.

Erez, J.: On the life history of Planktonic Foraminifera: lunar reproduction cycle in Globigerinoides sacculifer, Paleobiology, 6, 295-306, 1991.

Eynaud, F.: Planktonic foraminifera in the Arctic: potentials and issues regarding modern and quaternary populations, IOP Conf. Ser. Earth Environ. Sci., 14, 012005, https://doi.org/10.1088/1755-1315/14/1/012005, 2011.

Fehrenbacher, J. S., Russell, A. D., Davis, C. V., Spero, H. J., Chu, E., and Hönisch, B.: Ba/Ca ratios in the non-spinose planktic foraminifer Neogloboquadrina dutertrei: Evidence for an organic aggregate microhabitat, Geochim. Cosmochim. Ac., 236, 361372, https://doi.org/10.1016/j.gca.2018.03.008, 2018.

Field, D. B.: Variability in vertical distributions of planktonic foraminifera in the California current: Relationships to vertical ocean structure, Paleoceanography, 19, 1-22, https://doi.org/10.1029/2003PA000970, 2004.

Greco, M.: Concentration of Neogloboquadrina pachyderma from plankton tows during cruises NEWP-92, NEWP-93, ARK-IV/3, ARK-X/1, ARK-X/2, ARK$\mathrm{XI} / 2, \quad \mathrm{M} 36 / 3, \quad \mathrm{MSM} 09 / 2$, ARK-XXVI/1, PANGAEA, https://doi.pangaea.de/10.1594/PANGAEA.905270, 2019.

Hays, G. C.: A review of adaptive significance and ecosystem consequenses of zooplankton diel vertical migrations, Hydrobiologia, 503, 163-170, 2003.

Hemleben, C., Spindler, M., and Anderson, O. R.: Modern Planktonic Foraminifera, Springer, 1989.

Hillaire-Marcel, C.: Foraminifera isotopic records? with special attention to high northern latitudes and the impact of sea-ice distillation processes, IOP Conf. Ser. Earth Environ. Sci., 14, 1-9, https://doi.org/10.1088/1755-1315/14/1/012009, 2011.

Hillaire-Marcel, C., De Vernal, A., Polyak, L., and Darby, D.: Size-dependent isotopic composition of planktic foraminifers from Chukchi Sea vs. NW Atlantic sediments - Implications for the Holocene paleoceanography of the western Arctic, Quaternary Sci. Rev., 23, 245-260, https://doi.org/10.1016/j.quascirev.2003.08.006, 2004.

Hu, S. K., Connell, P. E., Mesrop, L. Y., and Caron, D. A.: A Hard Day's Night: Diel Shifts in Microbial Eukaryotic Activity in the North Pacific Subtropical Gyre, Front. Mar. Sci., 5, 1-17, https://doi.org/10.3389/fmars.2018.00351, 2018.

Hurrell, J. W., Holland, M. M., Gent, P. R., Ghan, S., Kay, J. E., Kushner, P. J., Lamarque, J.-F., Large, W. G., Lawrence, D., Lindsay, K., Lipscomb, W. H., Long, M. C., Mahowald, N.,
Marsh, D. R., Neale, R. B., Rasch, P., Vavrus, S., Vertenstein, M., Bader, D., Collins, W. D., Hack, J. J., Kiehl, J., and Marshall, S.: The Community Earth System Model: A Framework for Collaborative Research, B. Am. Meteorol. Soc., 94, 13391360, https://doi.org/10.1175/bams-d-12-00121, 2013.

Jensen, S.: Planktische Foraminiferen im Europäischen Nordmeer: Verbreitung und Vertikalfluß sowie ihre Entwicklung während der letzten 15000 Jahre, 1998.

Jonkers, L. and Kučera, M.: Global analysis of seasonality in the shell flux of extant planktonic Foraminifera, Biogeosciences, 12, 2207-2226, https://doi.org/10.5194/bg-12-2207-2015, 2015.

Jonkers, L., Reynolds, C. E., Richey, J., and Hall, I. R.: Lunar periodicity in the shell flux of planktonic foraminifera in the Gulf of Mexico, Biogeosciences, 12, 3061-3070, https://doi.org/10.5194/bg-12-3061-2015, 2015.

Kohfeld, K. E. and Fairbanks, R. G.: Neogloboquadrina Pachyderma (sinistral coiling) as Paleoceanographic Tracers in Polar Oceans: Evidence from Northeast Water Polynya Plankton Tows, Sediment Traps, and Surface Sediments, Paleoceanography, 11, 679-699, https://doi.org/10.1029/96pa02617, 1996.

Kozdon, R., Eisenhauer, A., Weinelt, M., Meland, M. Y., and Nürnberg, D.: Reassessing $\mathrm{Mg} / \mathrm{Ca}$ temperature calibrations of Neogloboquadrina pachyderma (sinistral) using paired $\delta{ }^{44 / 40} \mathrm{Ca}$ and $\mathrm{Mg} / \mathrm{Ca}$ measurements, Geochem. Geophy. Geosy., 10, 1-14, https://doi.org/10.1029/2008GC002169, 2009.

Kretschmer, K., Jonkers, L., Kucera, M., and Schulz, M.: Modeling seasonal and vertical habitats of planktonic foraminifera on a global scale, Biogeosciences, 15, 44054429, https://doi.org/10.5194/bg-15-4405-2018, 2018.

Kucera, M.: Planktonic Foraminifera as Tracers of Past Oceanic Environments, in: Developments in Marine Geology, Vol. 1, edited by: Hillaire-Marcel, C. and de Vernal, A., Elsevier, Amsterdam, 213-262, 2007.

Kucera, M., Rhein, M., and Gohl, K.: Oceanography and geodynamics in the NW Atlantic and the Baffin Bay - Cruise No. MSM09 - 23 July-29 October 2008 - Bremen (Germany) Ponta Delgada (Azores), 2014.

Lazaridis, E.: Package "lunar", version 0.1-04, available at: https: //cran.r-project.org/web/packages/lunar/lunar.pdf (last access: 2 September 2019), 2015.

Leu, E., Mundy, C. J., Assmy, P., Campbell, K., Gabrielsen, T. M., Gosselin, M., Juul-Pedersen, T., and Gradinger, R.: Arctic spring awakening - Steering principles behind the phenology of vernal ice algal blooms, Prog. Oceanogr., 139, 151-170, https://doi.org/10.1016/j.pocean.2015.07.012, 2015.

Locarnini, R. A., Misnov, A. V., Antonov, J. I., Boyer, T. P., Garcia, H. E., Baranova, O. K., Zweng, M. M., Paver, C. R., Reagan, J. R., Johnson, D. R., Hamilton, M., and Seidov, D.: World Ocean Atlas 2013, Volume 1: Temperature, NOAA Atlas NESDIS 73, Vol. 1, 40 pp., available at: http://www.nodc.noaa.gov/ OC5/indprod.html (last access: October 2018), 2013.

Manno, C. and Pavlov, A. K.: Living planktonic foraminifera in the Fram Strait (Arctic): Absence of diel vertical migration during the midnight sun, Hydrobiologia, 721, 285-295, https://doi.org/10.1007/s10750-013-1669-4, 2014.

Meilland, J., Siccha, M., Weinkauf, M. F. G., Jonkers, L., Morard, R., Baranowski, U., Baumeister, A., Bertlich, J., Brummer, G. J., Debray, P., Fritz-Endres, T., Groeneveld, J., Magerl, L., Munz, P., Rillo, M. C., Schmidt, C., Takagi, H., Theara, G., and Kucera, 
M.: Highly replicated sampling reveals no diurnal vertical migration but stable species-specific vertical habitats in planktonic foraminifera, J. Plank. Res., 41, 127-141, 2019.

Moore, J. K., Lindsay, K., Doney, S. C., Long, M. C., and Misumi, K.: Marine ecosystem dynamics and biogeochemical cycling in the community earth system model [CESM1(BGC)]: Comparison of the 1990s with the 2090s under the RCP4.5 and RCP8.5 scenarios, J. Clim., 26, 9291-9312, https://doi.org/10.1175/JCLI-D-12-00566.1, 2013.

Oksanen, J., Blanchet, F. G., Friendly, M., Kindt, R., Legendre, P., Mcglinn, D., Minchin, P. R., Hara, R. B. O., Simpson, G. L., Solymos, P., Stevens, M. H. H., and Szoecs, E.: vegan: Community Ecology Package, R package version (Version 2.5-2), http://CRAN.R-project.org/package=vegan, 2018.

Pados, T. and Spielhagen, R. F.: Species distribution and depth habitat of recent planktic foraminifera in Fram Strait, Arctic Ocean, Polar Res., 33, 22483, https://doi.org/10.3402/polar.v33.22483, 2014.

R Core Team: R:A language and environment for statistical computing. R Foundation for Statistical Computing, Vienna, Austria, available at: https://www.R-project.org/, 2017.

Rabindranath, A., Daase, M., Falk-Petersen, S., Wold, A., Wallace, M. I., Berge, J., and Brierley, A. S.: Seasonal and diel vertical migration of zooplankton in the High Arctic during the autumn midnight sun of 2008, Mar. Biodivers., 41, 365-382, https://doi.org/10.1007/s12526-010-0067-7, 2011.

Rebotim, A., Voelker, A. H. L., Jonkers, L., Waniek, J. J., Meggers, H., Schiebel, R., Fraile, I., Schulz, M., and Kucera, M.: Factors controlling the depth habitat of planktonic foraminifera in the subtropical eastern North Atlantic, Biogeosciences, 14, 827-859, https://doi.org/10.5194/bg-14-827-2017, 2017.

Schiebel, R., Bijma, J., and Hemleben, C.: Population dynamics of the planktic foraminifer Globigerina bulloides from the eastern North Atlantic, Deep-Sea Res. Pt. I, 44, 1701-1713, https://doi.org/10.1016/S0967-0637(97)00036-8, 1997.

Schiebel, R., Spielhagen, R. F., Garnier, J., Hagemann, J., Howa, H., Jentzen, A., Martínez-Garcia, A., Meilland, J., Michel, E., Repschläger, J., Salter, I., Yamasaki, M., and Haug, G.: Modern planktic foraminifers in the high-latitude ocean, Mar. Micropaleontol., 136, 1-13, https://doi.org/10.1016/j.marmicro.2017.08.004, 2017.

Simpson, G. and Chamberlain, M. S.: Package "pangaear", version 0.6.0, available at: https://github.com/ropensci/pangaear/ (last access: 2 September 2019), 2018.

Simstich, J., Sarnthein, M., and Erlenkeuser, H.: Paired $\delta^{18} \mathrm{O}$ signals of Neogloboquadrina pachyderma (s) and Turborotalita quinqueloba show thermal stratification structure in Nordic Seas, Mar. Micropaleontol., 48, 107-125, https://doi.org/10.1016/S0377-8398(02)00165-2, 2003.

Spindler, M., Hernleben, C., Bayer, U., Bé, A., and Anderson, O.: Lunar Periodicity of Reproduction in the Planktonic Foraminifer Hastigerina pelagica, Mar. Ecol. Prog. Ser., 1, 6164, https://doi.org/10.3354/meps001061, 1979.

Stangeew, E.: Distribution and isotopic composition of living planktonic foraminifera $N$. pachyderma (sinistral) and $T$. quinqueloba in the high latitude North Atlantic, PhD Thesis, Mathematisch-Naturwissenschaftliche Fakultät der Christian-Albrechts-Universität zu Kiel, Germany, 90 pp., urn:nbn:de:gbv:8-diss-4645, PS55/018,
https://doi.org/10.1594/PANGAEA.604861 https://doi.org/10.1594/PANGAEA.604862 https://doi.org/10.1594/PANGAEA.604827 https://doi.org/10.1594/PANGAEA.604864 https://doi.org/10.1594/PANGAEA.604829 https://doi.org/10.1594/PANGAEA.604866 https://doi.org/10.1594/PANGAEA.604867 https://doi.org/10.1594/PANGAEA.604832 https://doi.org/10.1594/PANGAEA.604833 https://doi.org/10.1594/PANGAEA.604834 https://doi.org/10.1594/PANGAEA.604871 https://doi.org/10.1594/PANGAEA.604872 https://doi.org/10.1594/PANGAEA.604837 https://doi.org/10.1594/PANGAEA.604839 https://doi.org/10.1594/PANGAEA.604840 https://doi.org/10.1594/PANGAEA.604877 15, https://doi.org/10.1594/PANGAEA.604854 M39/4_361CTD-18, https://doi.org/10.1594/PANGAEA.604817 M39/4_366CTD-22, https://doi.org/10.1594/PANGAEA.604856 M39/4_376CTD-29, https://doi.org/10.1594/PANGAEA.604857 M39/4_381CTD-34, https://doi.org/10.1594/PANGAEA.604842 M39/4_404CTD-57: https://doi.org/10.1594/PANGAEA.604860, 2001.

Taylor, B. J., Rae, J. W. B., Gray, W. R., Darling, K. F., Burke, A., Gersonde, R., Abelmann, A., Maier, E., Esper, O., and Ziveri, P.: Distribution and ecology of planktic foraminifera in the North Pacific: Implications for paleo-reconstructions, Quaternary Sci. Rev., 191, 256-274, https://doi.org/10.1016/j.quascirev.2018.05.006, 2018.

Tolderlund, D. S. and Bé, A. W. H.: Seasonal distribution of planktonic foraminifera in the western North Atlantic, Micropaleontology, 17, 297-329, 1971.

Volkmann, R.: Planktic Foraminifers in the Outer Laptev Sea and the Fram Strait-Modern Distribution and Ecology, J. Foramin Res., 30, 157-176, https://doi.org/10.2113/0300157, 2000.

Volkmann, R. and Stein, R.: Planktic foraminifera counts during POLARSTERN cruise ARK-XI/1, PANGAEA,https://doi.org/10.1594/PANGAEA.91119, 2003.

Volkmann, R. and Stein, R.: Planktic foraminifera counts during POLARSTERN cruise ARK-XIII/2, PANGAEA, https://doi.org/10.1594/PANGAEA.136881, 2004.

Weiner, A., Aurahs, R., Kurasawa, A., Kitazato, H., and Kucera, M.: Vertical niche partitioning between cryptic sibling species of a cosmopolitan marine planktonic protist, Mol. Ecol., 21, 40634073, https://doi.org/10.1111/j.1365-294X.2012.05686.x, 2012.

Xiao, W., Wang, R., Polyak, L., Astakhov, A., and Cheng, X.: Stable oxygen and carbon isotopes in planktonic foraminifera Neogloboquadrina pachyderma in the Arctic Ocean: An overview of published and new surface-sediment data, Mar. Geol., 352, 397-408, https://doi.org/10.1016/j.margeo.2014.03.024, 2014.

Žarić, S., Donner, B., Fischer, G., Mulitza, S., and Wefer, G.: Sensitivity of planktic foraminifera to sea surface temperature and export production as derived from sediment trap data, Mar. Micropaleontol., 55, 75-105, https://doi.org/10.1016/j.marmicro.2005.01.002, 2005. 